\title{
Remote ischaemic
} preconditioning: the current best hope for improved myocardial protection in cardiac surgery?

\author{
Ishtiaq Rahman, Robert S Bonser
}

Ischaemic preconditioning has been recognised as a major cardioprotective phenomenon for many years. ${ }^{12}$ Cycles of nonlethal ischaemia and reperfusion applied to the heart before a potentially lethal ischaemic insult have the ability to reduce infarct size by $>50 \%$. More recently, it became apparent that the protection generated by this classical form of direct ischaemic preconditioning could be replicated when the non-lethal ischaemia was applied to one segment of the heart and the lethal ischaemia applied to a separate segment. $^{3}$ Thereafter, it became established that the same protection could also occur even if the preconditioning ischaemic stimulus was applied completely distant from the target organ requiring protection - that is, transient ischaemia of a remote organ or limb could still generate protection for the organ being subsequently challenged by lethal ischaemia. ${ }^{4}$ There is now clinical evidence, suggesting that this remarkable remote ischaemic preconditioning (RIPC) phenomenon may represent a simple, inexpensive, easily applied method of increasing cardioprotection during an array of interventional procedures that require a period of cardiac ischaemia to allow repair or intervention. Moreover, as it is now recognised that such protection may be achieved by starting the cyclical remote ischaemia and reperfusion after the period of injurious cardiac ischaemia has started-so-called remote post- or periconditioning - the possibility arises of enhancing protection in other situations, including transplantation. ${ }^{5}$

Several clinical reports of RIPC in cardiovascular surgery have now been published. In children undergoing congenital heart defect repairs using cardiopul-

University Hospital Birmingham NHS Trust, Birmingham, UK

Correspondence to: Professor R S Bonser, Cardiopulmonary Unit, Queen Elizabeth Hospital Edgbaston, Birmingham B15 2TH, UK; robert.bonser@ uhb.nhs.uk monary bypass, lower limb RIPC has been shown to reduce troponin release and inotrope requirements. ${ }^{6}$ In adults undergoing coronary artery bypass (CABG) surgery, intermittent upper limb ischaemia has been followed by reductions in postoperative release of lactate dehydrogenase $^{7}$ and troponin T. ${ }^{8}$ In abdominal aortic aneurysm surgery, RIPC, induced by unilateral iliac artery clamping has reduced troponin release and renal injury.

In most of these studies the release of troponin is used as a marker of the quantum of injury suffered by the myocardium. Post-cardiac surgery troponin levels have been used to compare different myocardial protection strategies and provide an indicator of long-term outcome. ${ }^{10-}$ ${ }^{12}$ Which troponin metric - isolated values at specific time points or area under the curve (AUC) release-provides the most prognostically important information is not yet known. Additionally, whether troponin release in the first few hours after surgery reflects true infarction or a change in sarcolemmal integrity or permeability has been questioned. ${ }^{13}$

In this issue of Heart Venugopal et al ${ }^{14}$ provide further evidence that RIPC may improve myocardial protection in humans (see page 1567). This single-centre randomised trial studied RIPC or a placebo intervention in 45 patients undergoing CABG with or without concomitant aortic valve replacement (AVR) as an adjunct to antegrade \pm retrograde blood cardioplegia myocardial protection. Patients with diabetes, renal, hepatic or pulmonary dysfunction were excluded as were those with unstable angina or myocardial infarction within 4 weeks of surgery.

The remote preconditioning stimulus comprised three 5 min cycles of forearm ischaemia, induced by inflating a blood pressure cuff on the upper arm to $200 \mathrm{~mm}$ $\mathrm{Hg}$, with an intervening 5 min reperfusion. The control group had a deflated cuff placed on the upper arm for $30 \mathrm{~min}$. On parametric analysis, RIPC was found to reduce the area under the curve (AUC) serum cardiac troponin $\mathrm{T}$ (cTn $\mathrm{T}$ ) release by $>40 \%$. The magnitude of the effect was similar to that seen in a cohort of patients undergoing intermittent ischaemic arrest as a mode of myocardial protection, reported by the same group previously. ${ }^{8}$ Unfortunately, clinical outcomes are not reported.

On the basis of this and other work, there is now a need (a) to determine the efficacy of RIPC in promoting protection in other forms of cardiac surgery; $(b)$ to ascertain whether the changes in troponin release are reproducible in other studies; (c) to establish if these changes are reflected in improved clinical outcomes and that RIPC independently reduces risk. ${ }^{15}$ However, before these studies are designed and started the design and analysis of this study require some further comment.

First, blinding of treatment allocation was applied to patients and surgeons only; anaesthetists (who administer agents capable of preconditioning or affecting myocardial protection) and investigators were not blinded. Similar proportions of patients received isoflurane or servoflurane for anaesthetic maintenance but dosages were not reported. As such volatile anaesthetic agents may induce a dose-dependent conditioning effect, ${ }^{16}$ a potential for inadvertent bias arises. Second, the study was small and contained only half of the estimated number of patients to detect the initially expected difference in AUC cTnT of $15 \mu \mathrm{g} / 1.72 \mathrm{~h}$ (standard deviation $25 \mu \mathrm{g} /$ $1.72 \mathrm{~h}$ ) quoted in the statistical methodology. Statistical significance was actually attained with a smaller mean difference and sample size and this is attributable to the lower than expected variance seen in the RIPC group. Third, the study also included patients requiring AVR; whether RIPC was effective in the patients undergoing $\mathrm{CABG}$ alone is not reported. The larger number of combined AVR/CABG cases contributed to a longer mean bypass time in the control group and bypass time was an independent predictor of greater troponin release. Despite this potentially confounding effect, an intergroup statistically significant difference was maintained after correction for bypass time using a generalised linear model. Fourth, many of the important variables in the study-for example, bypass time, crossclamp time and AUC cTnT had unequal variances yet were analysed parametrically unlike the authors' previous report. Lastly, although the drug history is reported, whether potentially relevant 
drugs-for example, atorvastatin, potassium channel blockers, ${ }^{17}{ }^{18}$ were administered in the $24 \mathrm{~h}$ preoperatively is not clear.

Nevertheless, the effect of RIPC on troponin release was large and the data are very encouraging. In particular, the troponin effect was observed despite the use of halogenated anaesthetic gases in the majority of patients. Several studies have demonstrated that such volatile anaesthetic agents may reduce evidence of myocardial injury during CABG through what is thought to be a preconditioning mechanism. ${ }^{19-21}$ Thus, this study is important as it suggests that the effect of RIPC is, at least additive to any protective effect afforded by isoflurane and servoflurane.

So, can RIPC fulfil the promise of improved myocardial protection where its predecessor cardiac same-organ ischaemic preconditioning stumbled? In early studies, classical ischaemic preconditioning alone was reported to reduce troponin release, ${ }^{22} 23$ improve high-energy phosphate conservation and reduce inotrope requirement. Such benefits suggested that ischaemic preconditioning could not only reduce infarct size but also attenuate reversible sublethal myocardial injury. These effects were corroborated in some but not all studies. ${ }^{24-28}$ The clinical effect, however, was less obvious and was in some reports detrimental ${ }^{29}$ and thus the inclusion of classical ischaemic preconditioning in the armamentarium of surgical myocardial protection was frustrated. If RIPC is to gain a role in surgical myocardial protection, it must achieve measurable effects on both biochemical indicators and other manifestations of cardiac injury, including function, low cardiac output incidence and improved recovery rates.

How then does RIPC achieve its beneficial effects and might these be applicable across the spectrum of cardiac surgery? The mechanism of RIPC has not as yet been entirely unravelled ${ }^{5}$ but one of the most pertinent questions is how the signal from the remote conditioning site is transferred to the target organ. There is evidence for both humoral mediation and neurogenic pathways. Certainly, innervation of the conditioning site ${ }^{3031}$ and heart reperfusion appear to be prerequisites of cardioprotection. In most cardiac surgery, both these requirements are fulfilled. Therefore, if the findings of this study are corroborated by larger trials, the great potential of RIPC could be realised. Transplantation represents a specific challenge to a therapeutic role of RIPC. Theoretically, RIPC could be used in the brainstem dead donor to generate cardioprotection. However, although the preconditioning site would remain innervated, central neural connection is lost. Moreover, in this circumstance, reperfusion does not occur in the preconditioned environment unless the stimulus is repeated in the recipient. This is indeed the case, a donor heart, denervated at transplantation may still be protected from a postimplantation ischaemic insult by an RIPC stimulus in the recipient. ${ }^{32}$ However, whether such conditioning could protect during the retrieval, transport and implant period of transplantation is not clear.

The data accruing thus far for RIPC in both the medical and surgical cardiological arenas are promising and at present it appears to be one of the most important potential myocardial protective adjuncts so far identified..$^{34}$ Let us be sure to investigate its role, comprehensively, throughout cardiac surgery, in large studies with clinical end points.

Funding: No funders related to this article. RSB has received British Heart Foundation grant funding for studies in remote preconditioning.

Competing interests: None declared.

Provenance and peer review: Commissioned; externally peer reviewed.

Accepted 28 April 2009

Published Online First 22 July 2009

Heart 2009;95:1553-1555.

doi:10.1136/hrt.2008.159988

\section{REFERENCES}

1. Murry CE, Jennings RB, Reimer KA. Preconditioning with ischemia: a delay of lethal injury in ischemic myocardium. Circulation 1986;74:1124-36.

2. Yellon DM, Downey JM. Preconditioning the myocardium: from cellular physiology to clinical cardiology. Physiol Rev 2003;83:1113-51.

3. Przyklenk K, Bauer B, Ovize M, et al. Regional ischemic 'preconditioning' protects remote virgin myocardium from subsequent sustained coronary occlusion. Circulation 1993;87:893-9.

4. Przyklenk K, Darling CE, Dickson EW, et al. Cardioprotection 'outside the box' - the evolving paradigm of remote preconditioning. Basic Res Cardiol 2003;98:149-57.

5. Hausenloy DJ, Yellon DM. Remote ischaemic preconditioning: underlying mechanisms and application. Cardiovasc Res 2008;79:377-86.

6. Cheung MMH, Kharbanda RK, Konstantinov IE, et al. Randomized controlled trial of the effects of remote ischemic preconditioning on children undergoing cardiac surgery: first clinical application in humans J Am Coll Cardiol 2006;47:2277-82.

7. Gunaydin B, Cakici I, Soncul H, et al. Does remote organ ischaemia trigger cardiac preconditioning during coronary artery surgery? Pharmacol Res 2000;41:493-6.

8. Hausenloy DJ, Mwamure PK, Venugopal V, et al. Effect of remote ischaemic preconditioning on myocardial injury in patients undergoing coronary artery bypass graft surgery: a randomised controlled trial. Lancet 2007;370:575-9.

9. Ali ZA, Callaghan CJ, Lim E, et al. Remote ischemic preconditioning reduces myocardial and renal injury after elective abdominal aortic aneurysm repair: a randomized controlled trial. Circulation 2007:116:I-98-105.
10. Jacquet L, Noirhomme P, El Khoury G, et al. Cardiac troponin I as an early marker of myocardial damage after coronary artery bypass surgery. Eur J Cardiothorac Surg 1998:13:378-84.

11. Fellahi JL, Gué X, Richomme $X$, et al. Short- and long-term prognostic value of post-operative cardiac troponin I concentration in patients undergoing coronary artery bypass grafting. Anesthesiology 2003:99:270-4

12. Lehrke S, Steen H, Sievers HH, et al. Cardiac troponin $\mathrm{T}$ for prediction of short- and long-term mortality after elective open heart surgery. Clin Chem 2004;50:1560-7

13. Taggart DP, Neubauer S, Costa MA, et al. Incidence, predictors, and significance of abnormal cardiac enzyme rise in patients treated with bypass surgery in the Arterial Revascularization Therapies Study (ARTS) * Response. Circulation 2002;106:55e-56.

14. Venugopal V, Hausenloy DJ, Ludman A, et al. Remote ischaemic preconditioning reduces myocardial injury in patients undergoing cardiac surgery with cold-blood cardioplegia: a randomised controlled trial. Heart 2009;95:1567-71.

15. Christakis GT, Fremes SE, Naylor WG. Impact of pre-operative risk and peroperative morbidity on ICU stay following coronary artery bypass surgery. Cardiovasc Surg 1996;4:29-35.

16. Kehl F, Krolikowski JG, Mraovic B, et al. Is isofluraneinduced preconditioning dose related? Anesthesiology 2002;96:675-80.

17. Bell RM, Yellon DM. Atorvastatin, independent of lipid lowering, protects the myocardium when given at reperfusion by upregulating a prosurvival pathway. J Am Coll Cardiol 2003;41:508-15.

18. Sakai K, Yamagata T, Teragawa $\mathrm{H}$, et al. Nicorandilinduced preconditioning as evidenced by troponin $\mathrm{T}$ measurements after coronary angioplasty in patients with stable angina pectoris. Jpn Heart J 2002;43:443-53

19. Belhomme D, Peynet J, Louzy M, et al. Evidence for preconditioning by isoflurane in coronary artery bypass surgery. Circulation 1999;100:II-340-4.

20. Lee MC, Chen $\mathrm{CH}$, Kuo MC, et al. Isoflurane preconditioning-induced cardioprotection in patients undergoing coronary artery bypass grafting. Eur J Anaesthiol 2006;23:841-7.

21. Tritapepe L, Landoni G, Guarracino F, et al. Cardiac protection by volatile anaesthetics; a multicentre randomized controlled study in patients undergoing coronary artery bypass grafting with cardiopulmonary bypass. Eur J Anaesthiol 2007;24:323-31.

22. Yellon DM, Alkhulaifi AM, Pugsley WB. Preconditioning the human myocardium. Lancet 1993;342:276-83

23. Jenkins DP, Pugsley WB, Alkhulaifi AM, et al. Ischemic preconditioning reduces troponin T release in patients undergoing coronary artery bypass surgery. Heart 1997;77:314-8.

24. Illes RW, Swoyer KD. Prospective randomized clinical study of ischemic preconditioning as an adjunct to intermittent cold blood cardioplegia. Ann Thorac Surg 1998;65:748-53.

25. Lu EX, Chen SX, Yuan MD, et al. Preconditioning improves myocardial preservation in patients undergoing open heart operations. Ann Thorac Surg 1997:64:1320-4.

26. Li G, Chen $\mathrm{S}$, Lu E, et al. Ischemic preconditioning improves preservation with cold blood cardioplegia in valve replacement patients. Eur J Cardiothorac Surg 1999;15:653-7.

27. Teoh LKK, Grant R, Hulf JA, et al. A comparison between ischemic preconditioning, intermittent cross cmap fibrillation and cold crystalloid cardioplegia for myocarial protection during coronary artery bypass surgery. Cardiovasc Surg 2002;10:251-5

28. Ghosh S, Galinanes M. Protection of the human heart with ischemic preconditioning during cardiac surgery: role of cardiopulmonary bypass. J Thorac Cardiovasc Surg 2003:126:133-42.

29. Perrault LP, Menasche P, Bel A, et al. Ischemic preconditioning in cardiac surgery: a word of caution. J Thorac Cardiovasc Surg 1996;112:1378-86. 
30. Gho BC, Schoemaker RG, van den Doel MA, et al. Myocardial protection by brief ischemia in non-cardiac tissue. Circulation 1996:94:2193-200.

31. Birnbaum Y, Hale SL, Kloner RA. Ischemic preconditioning at a distance: reduction of myocardial infarct size by partial reduction of blood supply combined with rapid stimulation of the gastrocnemius muscle in the rabbit. Circulation 1997:96:1641-6.

32. Konstantinov IE, Li J, Cheung M, et al. Remote ischaemic preconditioning of the recipient reduces myocardial ischemia-reperfusion injury of the denervated heart via a $K_{\text {ATP }}$ channel-dependent mechanism. Transplantation 2005;79:1691-5.
33. Hoole SP, Heck PM, Sharples L, et al. Cardiac Remote Ischemic Preconditioning in Coronary Stenting (CRISP Stent) study: a prospective, randomized control trial. Circulation 2009;119:820-7.

34. Kloner RA. Clinical application of remote ischemic preconditioning. Circulation 2009;119:776-8.

\section{Education in Heart: 10th anniversary}

Education in Heart (EIH) first appeared in this journal 10 years ago, since when it has been one of our flagship sections, comprising articles that have regularly been among the most widely accessed of Heart's published output. Throughout this period it has been edited semi-autonomously-and very successfully-by Peter Mills, who is now standing down, the baton passing to Jeroen Bax who takes over this month. EIH's 10th anniversary is a suitable time to look back at its achievements and those of its departing editor whose key contribution has been to identify an international cadre of opinion leaders able to produce material that goes beyond the traditional review process into areas specifically designed to educate. This has required not only subspecialty expertise on the part of the authors but also considerable editorial skill, ensuring that the contemporary content of EIH is presented in clear, unambiguous prose, with careful structuring, relevant illustration and annotated references to direct the reader to key source material. To underpin EIH's educational agenda Peter Mills has commissioned all articles against national and European curricula to ensure the requirements of our readership are fully met, with proper regard to both mainstream and Cinderella subject matter and to the need for updates, particularly in areas where new discoveries are proceeding most rapidly. The formal stamp of educational approval has been delivered through submission of all articles to the European Board for Accreditation in Cardiology (EBAC) in order to obtain European continuing medical education (CME) accreditation, with multiple-choice questions available at a dedicated web address. EIH is also scheduled to play a central role in the European revalidation initiative currently under development. We now welcome Jeroen Bax as the new Editor of EIH and acknowledge the work of Peter Mills in its evolution these last 10 years.

\section{Adam D Timmis}

Correspondence to: Professor A D Timmis, Editor, Heart; adamtimmis@mac.com Heart 2009;95:1555. doi:10.1136/hrt.2009.179812 